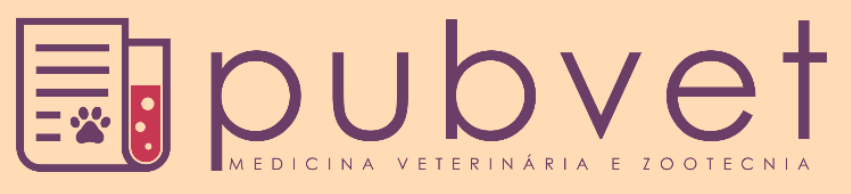

https://doi.org/10.31533/pubvet.v14n7a609.1-6

\title{
Penectomia total para tratamento de parafimose crônica em cão: relato de caso
}

\author{
Cleyson Teófilo Braga Filho ${ }^{1 *}$, Priscila Sales Braga $^{2} \bullet$, Camila Lacerda Soares $^{1 \bullet}$, Sérgio \\ Santalucia $^{30}$
}

${ }^{1}$ Médico Veterinário Graduado em Medicina Veterinária pela Universidade Estadual do Ceará

${ }^{2}$ Graduando em Medicina Veterinária pela Universidade Estadual do Ceará

${ }^{3}$ Médico Veterinário Mestre em Medicina Veterinária pela Universidade Federal de Santa Maria

*Autor para correspondência: E-mail: cleysont@gmail.com

\begin{abstract}
Resumo. As afecções que atingem o sistema reprodutor geram diversos problemas aos animais, passando a serem fontes de preocupação para os tutores. A parafimose é uma das patologias mais comuns que afeta o órgão genital masculino, atingindo cães de diferentes raças e idades, podendo apresentar causas congênitas ou adquiridas. A enfermidade se caracteriza pela exposição permanente do pênis canino, que não retorna à cavidade prepucial. No entanto, sua evolução pode ser em etapas, de tal forma que o tratamento de eleição dependerá da gravidade do caso, podendo ser tanto clínico quanto cirúrgico. $\mathrm{O}$ diagnóstico é feito através da inspeção visual associada ao relato do tutor. Nos casos de parafimoses de longa duração, que são acompanhadas de comprometimento tecidual, tornase necessário a amputação peniana total ou parcial. Com isso, o presente trabalho tem como objetivo relatar um caso de parafimose em um cão, que foi atendido em uma clínica particular na cidade de Crateús-Ce, apresentando histórico de exposição peniana em um período de aproximadamente 10 dias. Dentre outros sintomas que o animal apresentava, ao exame físico, foi evidenciada uma lesão fibrosa extensa, de aspecto proliferativo, acometendo toda superfície da glande e óstio uretral externo. Diante do diagnóstico definitivo para parafimose, e tendo em vista o estágio que se encontrava, o tratamento de eleição consistiu na cirurgia de penectomia total associada à uretrostomia escrotal, o qual proporcionou uma ótima recuperação e boa resposta do paciente.
\end{abstract}

Palavras chave: amputação, pênis, uretrostomia

\section{Total penectomy for chronic paraphimosis treatment in dogs: case report}

Abstract. Disorders that affect the reproductive system generate a lot of problems for animals and become a source of concern for tutors. Paraphimosis is one of the most common diseases that affect the genital organ, because it affects dogs of different breeds and ages, and it has a congenital or acquired causes. The disease is characterized by permanent exposure of the canine penis, which does not return to the preputial cavity. However, its evolution may be in stages, such as that the treatment of choice will depend on the severity of the case, and may be both clinical and surgical. Diagnosis is made through visual inspection associated with the tutor's report. In cases of long-term paraphymoses, which are accompanied by tissue involvement, total or partial penile amputation becomes necessary. Therefore, this paper has the objective of report a case of paraphimosis in a dog, which was treated at a private clinic in the city of Crateús-Ce, presenting a story of penile exposure over a period of approximately 10 days. Among the other symptoms that the animal had on physical examination, an extensive fibrous lesion, which a proliferative aspect was observed, affecting the entire mucosa of the glans and external urethral orifice. Giving the definitive diagnosis for paraphimosis, and considering the current stage, the real 
choice was consisted of total penectomy surgery associated with scrotal urethrostomy, which provided a great recovery and a great patient response.

Keywords: amputation, penis, urethorstomy

\section{Penectomía total para el tratamiento de la parafimosis crónica en un perro: reporte de un caso}

Resumen. Las enfermedades que afectan el sistema reproductivo generan varios problemas para los animales, convirtiéndose en una fuente de preocupación para los tutores. La parafimosis es una de las patologías más comunes que afecta el órgano genital masculino, afecta a perros de diferentes razas y edades, y puede tener causas congénitas o adquiridas. La enfermedad se caracteriza por la exposición permanente del pene canino, que no regresa a la cavidad prepucial. Sin embargo, su evolución puede ser en etapas, de tal manera que el tratamiento elegido dependerá de la gravedad del caso, y puede ser tanto clínico como quirúrgico. El diagnóstico se realiza mediante inspección visual asociada con el informe del tutor. En casos de parafimosis a largo plazo, que se acompañan de afectación tisular, es necesaria la amputación total o parcial del pene. Por lo tanto, este estudio tiene como objetivo informar un caso de parafimosis en un perro, que fue examinado en una clínica privada en la ciudad de Crateús-Ce, presentando un historial de exposición al pene durante un período de aproximadamente 10 días. Entre otros síntomas que presentaba el animal, en el examen físico, se detectó una extensa lesión fibrosa, con aspecto proliferativo, que afectaba toda la superficie del glande y el orificio uretral externo. En vista del diagnóstico definitivo de parafimosis, y de la etapa en la que se encontraba, el tratamiento de elección consistió en una cirugía de penectomía total asociada con uretrostomía escrotal, que proporcionó una excelente recuperación y una buena respuesta del paciente.

Palabras clave: amputación, pene, uretrostomía

\section{Introdução}

A parafimose é a incapacidade de retração pênis para o interior do prepúcio. Dentre os principais fatores etiológicos podemos citar alterações neurológicas, corpos estranhos, traumas, neoplasias, pseudo-hermafroditismo, constrição do pênis por pelos prepuciais e cópula recente. As alterações locais reduzem o orifício prepucial e impossibilitam a retração do pênis, gerando edema e prejuízos à irrigação, o que pode causar necrose. A exposição peniana prolongada torna o órgão sujeito a trauma externo A prevalência maior é em cães, sendo menos frequente em gatos (MacPhail, 2014; Volpato et al., 2010).

O histórico do paciente e a inspeção visual funcionam como forma de diagnóstico, sendo as alterações facilmente detectadas no exame clínico (Nelson \& Couto, 2015). A parafimose deve ser diferenciada de priapismo, trombose vascular, uretrite crônica, esticamento ou fraqueza do músculo retrator do pênis e músculos prepuciais hipoplásicos ou cirurgicamente traumatizados. Deve-se suspeitar de causas mecânicas quando o pênis é facilmente retraído. A inspeção visual simples, com a palpação do pênis, junto ao histórico do tutor é normalmente suficiente para diferenciar as condições (MacPhail, 2014; Nelson \& Couto, 2015).

O tratamento conservativo baseia-se na tentativa de realizar o reposicionamento do pênis no prepúcio e a minimização do inchaço. Nos casos em que o tratamento conservativo não apresenta sucesso, o tratamento de eleição é o cirúrgico (Gavioli et al., 2014; Papazoglou \& Kazakos, 2002). Os métodos cirúrgicos mais comuns são a reconstrução prepucial, a falopexia e a amputação do pênis. A castração é recomendada para evitar a recorrência da parafimose devido à atividade sexual (MacPhail, 2014). Em enfermidades crônicas, em que há extensa perda cutânea e lesão de ramos vasculares prepuciais e dorsais do pênis, a amputação se faz necessária (Volpato et al., 2010).

Diante da ocorrência da parafimose em cães e das complicações que esta enfermidade pode gerar, o objetivo do presente trabalho foi relatar um caso crônico de parafimose traumática em cão tratado com a técnica de penectomia total. 


\section{Relato do caso clínico}

Foi atendido um paciente macho, canino, castrado, sem raça definida, com 8 anos de idade, pesando $18 \mathrm{~kg}$ em uma clínica veterinária na cidade de Crateús-CE. O animal era criado em zona rural, apresentava controle de endoparasitas e ectoparasitas atrasados, não vacinado, alimentação constituída à base de ração e comida caseira, água fornecida ad libitum, além de histórico médico de erliquiose.

O animal apresentava histórico de exposição peniana há, aproximadamente 10 dias. Segundo o tutor, antes do ocorrido, o animal apresentava um ferimento na porção distal do pênis, que teria sido ocasionada por uma lesão cortante provocada por cerca de arame farpado. Após o ocorrido, o tutor relatou que a lesão piorou após o animal realizar mordedura no órgão afetado. Na anamnese, o proprietário informou que o animal apresentava anorexia, apatia e retenção urinária há 2 dias. Na avaliação física o mesmo apresentava depressão, linfonodos palpáveis, escore corporal 2, aferido 150 batimentos cardíacos e 56 movimentos respiratórios por minuto, com tempo de perfusão capilar menor que três segundos, pulso fraco e temperatura retal de $39,5^{\circ} \mathrm{C}$.

Durante o exame físico pôde-se evidenciar uma lesão fibrosa extensa, de aspecto proliferativo, acometendo toda superfície da glande e óstio uretral externo, ocasionando exposição de $50 \%$ do pênis, com presença de edema. O animal apresentava desconforto na palpação abdominal, sendo possível evidenciar o acumulo de urina na vesícula urinária. No ambulatório tentou-se realizar uma sondagem por via uretral para eliminação da urina retida, no entanto, percebeu-se resistência durante a passagem da sonda devido a lesão fibrótica presente no óstio uretral externo, e com isso, estenose do canal uretral, sendo necessária a realização de uma cistocentese.

Diante do histórico do paciente e do exame físico diagnosticou-se a parafimose traumática. Optouse pelo tratamento cirúrgico com a realização da penectomia total, tendo em vista o estágio crônico que o pênis se encontrava com presença de comprometimento tecidual e estenose uretral. Para realização do procedimento cirúrgico foram solicitados alguns exames hematológicos, como hemograma e bioquímica sérica (creatinina, alanina aminotransferase e proteínas totais).

\section{Resultados}

Os resultados laboratoriais revelaram hiperproteinemia e neutrofilia com desvio à esquerda, sendo que os demais parâmetros hematológicos e bioquímicos apresentaram níveis considerados normais para a espécie.

Após a realização e análise de todos esses exames, o animal foi encaminhado no dia seguinte para cirurgia em jejum hídrico e sólido de aproximadamente oito horas. Antes do início da cirurgia, foi aferida a temperatura retal, que foi de $39,5^{\circ} \mathrm{C}$ e frequência cardíaca que foi de 160 batimentos por minuto. $O$ paciente foi previamente tricotomizado e como pré-anestesia, foram aplicados metadona $(0,3$ $\mathrm{mg} / \mathrm{kg})$ e acepromazina $(0,02 \mathrm{mg} / \mathrm{kg})$ por via intramuscular. Para a indução anestésica, foi utilizado o propofol $(3 \mathrm{mg} / \mathrm{kg})$ e citrato de fentanila $(2 \mu \mathrm{g} / \mathrm{kg})$ por via endovenosa. A manutenção anestésica foi feita por via inalatória com uso do isoflurano. Foi utilizado também o bloqueio epidural com a associação de lidocaína $(4 \mathrm{mg} / \mathrm{kg})$ e morfina $(0,1 \mathrm{mg} / \mathrm{kg})$. Foi utilizado cefalotina $(30 \mathrm{mg} / \mathrm{kg})$ por via endovenosa antes do início do procedimento cirúrgico, e o acesso mantido com fluidoterapia com soro ringer com lactato.

Com o animal já em decúbito dorsal sobre a mesa cirúrgica, foi realizada a antissepsia da região retroumbilical com o uso de digluconato de clorexidina a $2 \%$ (Figura 1). Com uma lâmina de bisturi $\mathrm{n}^{\circ}$ 23 realizou-se uma incisão elíptica ao redor do prepúcio e escroto, associada à divulsão com tesoura Metzembaum até a base do pênis (Figura 2). A ligadura dos vasos para hemostasia e a ligadura dos vasos adjacentes ao pênis e bulbo foram realizadas com náilon 3-0. Devido à obstrução do orifício uretral foi necessário realizar uma incisão em estocada com uma lâmina de bisturi número 15 na região do corpo do pênis (Figura 3 ) para colocação de uma sonda uretral n 10 , para servir de referência no transoperatório (Figura 4).

Para evitar o extravasamento de urina, realizou-se uma cistocentese antes da sondagem. A incisão sobre a face ventral da uretra foi realizada com a lâmina de bisturi e amplificada com tesoura Metzenbaum. Em seguida, cerca de dois centímetros (caudalmente à amputação peniana) realizou-se 
uretrostomia em região escrotal, suturando uretra com pele, empregando-se pontos interrompidos simples, com fio de náilon 3-0.

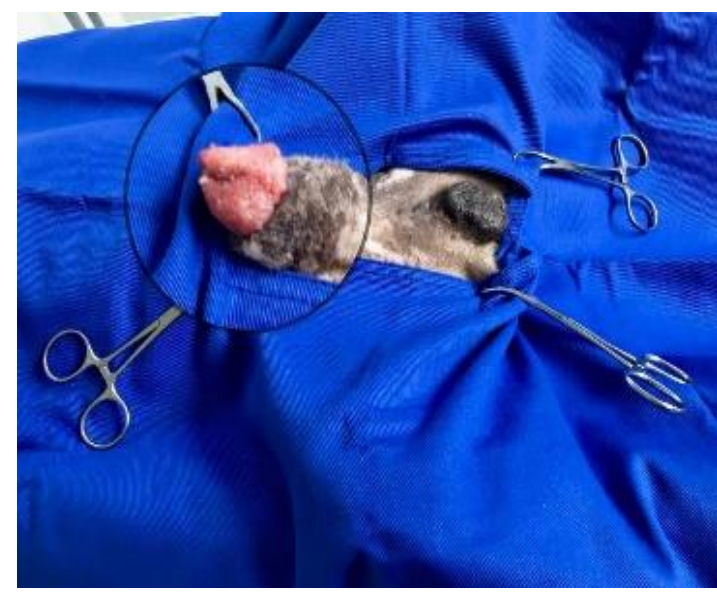

Figura 1. Imagem fotográfica de Cão, macho, castrado, 8 anos, $18 \mathrm{~kg}$. Animal em decúbito dorsal mostrando o aspecto inicial do pré-operatório. Visualização de regiões de fibrose na região da glande

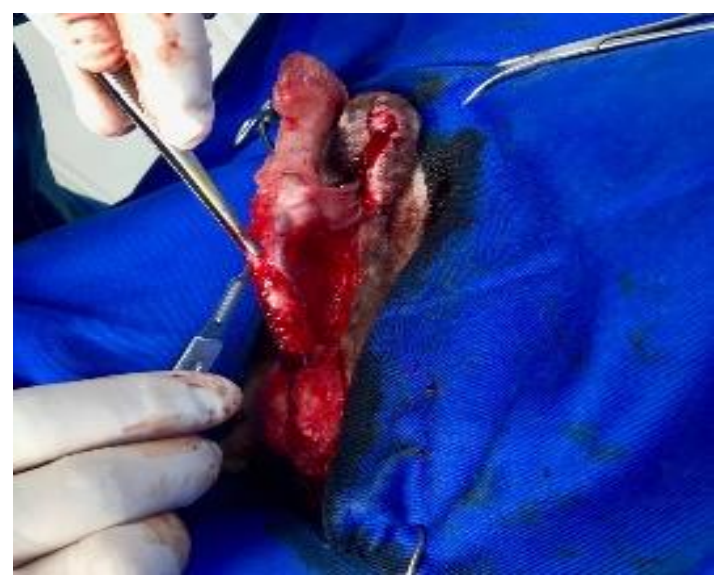

Figura 3. Imagem fotográfica de cão, macho, castrado, oito anos, $18 \mathrm{~kg}$. Incisão em estocada com a lâmina de bisturi no corpo do pênis

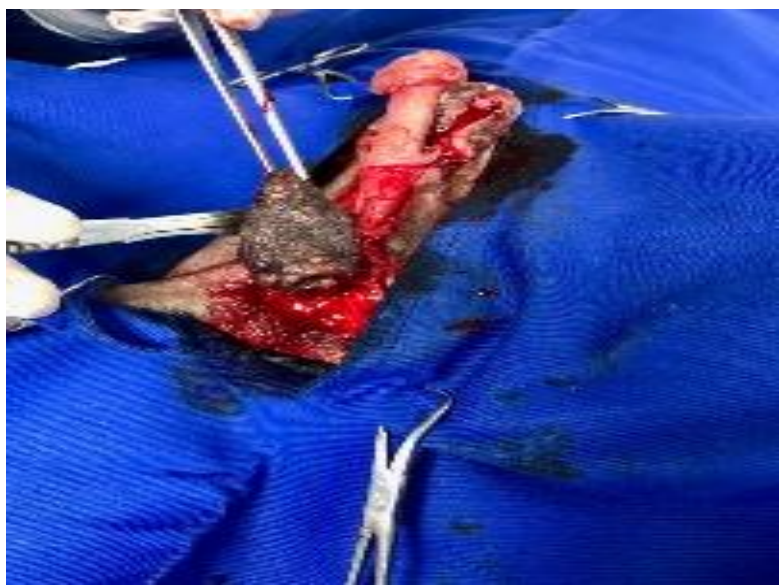

Figura 2. Imagem fotográfica de Cão, macho, castrado, 8 anos, $18 \mathrm{~kg}$. Incisão elíptica ao redor do prepúcio e escroto

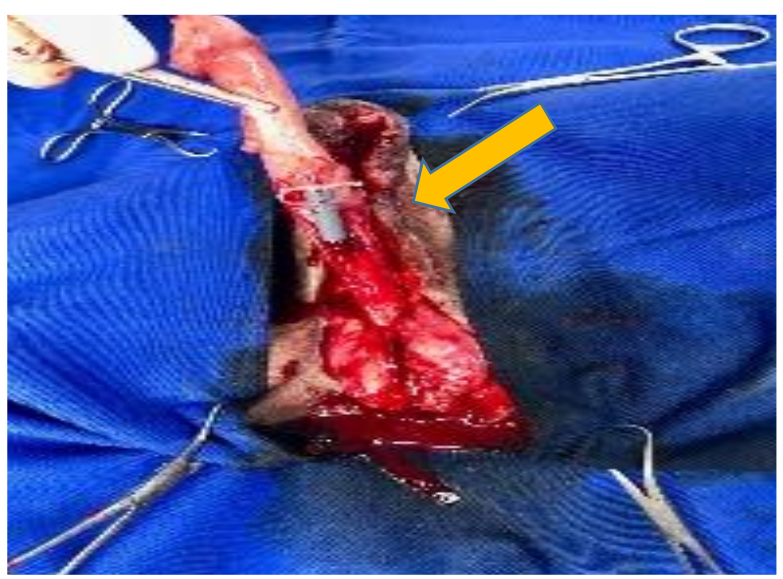

Figura 4. Imagem fotográfica de Cão, macho, castrado, 8 anos, $18 \mathrm{~kg}$. Implantação da sonda (indicada com seta amarela) uretral no corpo do pênis

A amputação do pênis foi realizada através da incisão em $\mathrm{V}$ do coto peniano. Foi realizada a aposição do coto peniano com a túnica albugínea mais síntese junto ao tecido subcutâneo (Figura 5). Foi executada redução do espaço morto, seguido de síntese cutânea do restante da pele. O animal foi mantido sondado, sendo fixada a sonda por meio de uma sutura em bailarina, e recomendado a retirada da sonda 72 horas após a cirurgia (Figura 6). Após o término do procedimento, foi aplicado cloridrato de tramadol $(4 \mathrm{mg} / \mathrm{kg})$ por via endovenosa e dipirona $(25 \mathrm{mg} / \mathrm{kg})$ por via intramuscular.

Para uso domiciliar, prescreveu-se as medicações orais: cefalexina $(20 \mathrm{mg} / \mathrm{kg})$, durante 15 dias (BID); dipirona ( $25 \mathrm{mg} / \mathrm{kg}$ ), durante 5 dias (TID); tramadol ( $4 \mathrm{mg} / \mathrm{kg}$ ), durante 5 dias (TID) e Meloxicam $(0,1 \mathrm{mg} / \mathrm{kg})$ durante cinco dias (SID). Foi solicitado ao proprietário que fosse feita limpeza da ferida cirúrgica com solução fisiológica de cloreto de sódio $0,9 \%$ e spray a base de clorexidina (BID), manter o animal em repouso, usar o colar elisabetano até a completa cicatrização e retirada dos pontos, alimentar o cão normalmente, além de não deixá-lo ter contato com areia. $O$ paciente retornou com 72 horas para retirada da sonda, não sendo identificada a deiscência de nenhum dos pontos.

Catorze dias após a cirurgia, o animal retornou à clínica para a retirada dos pontos, onde observouse que haviam alguns pontos inflamados, no entanto não havia presença de secreções visíveis (Figura 7). $\mathrm{O}$ animal se apresentava bem, sem dificuldade para urinar e sem incontinência urinária. $\mathrm{O}$ 
proprietário relatou a presença de algumas hemorragias durante a micção nos primeiros 10 dias pós procedimento cirúrgico, no entanto essas já haviam sido interrompidas.

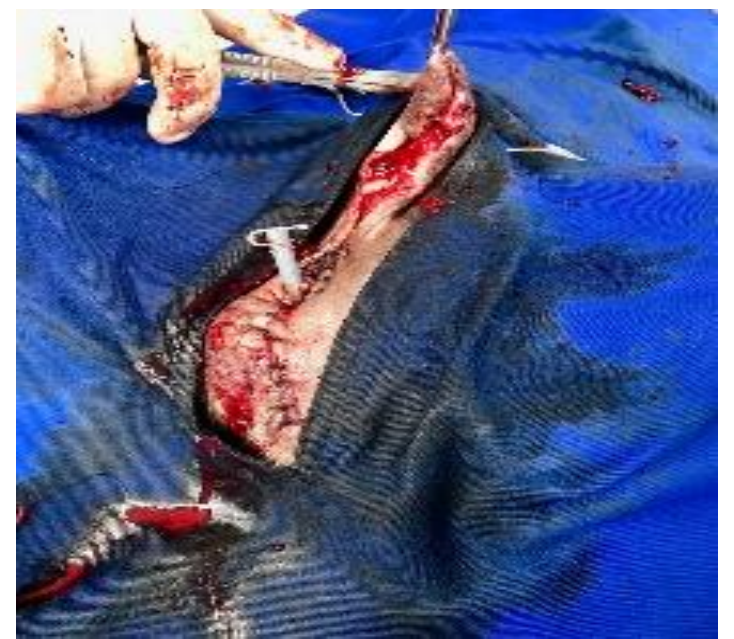

Figura 5. Imagem fotográfica de Cão, macho, castrado, 8 anos, $18 \mathrm{~kg}$. Ressecção do prepúcio após uretrostomia e amputação do pênis

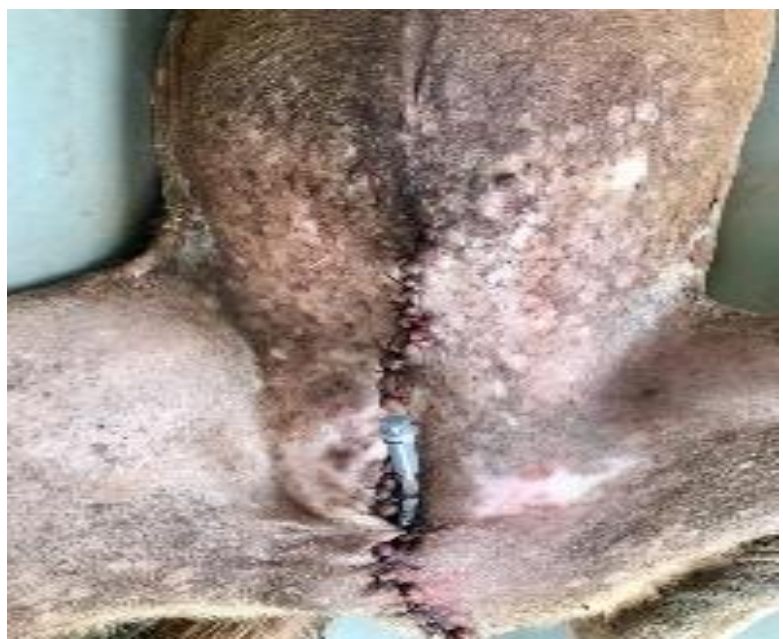

Figura 6. Imagem fotográfica de Cão, macho, castrado, 8 anos, $18 \mathrm{~kg}$. Aspecto final da cirurgia

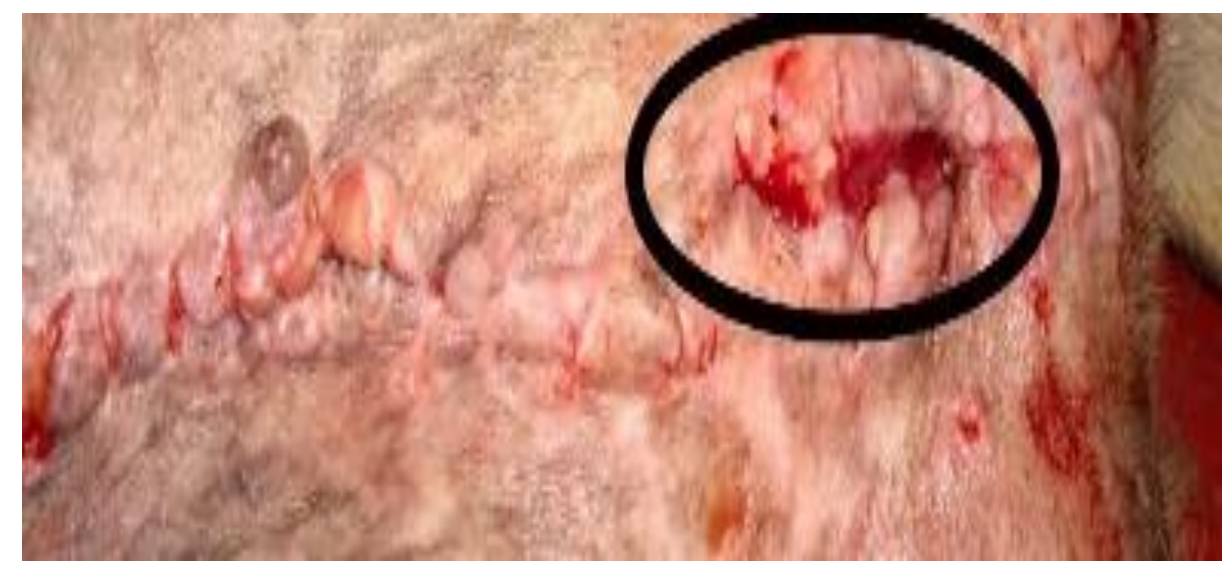

Figura 7. Imagem fotográfica de Cão, macho, castrado, 8 anos, 18kg. Aspecto da uretrostomia 14 dias pós procedimento cirúrgico

Durante o período de 90 dias foi mantido contato com o proprietário, o qual pode-se continuar monitorando o pós-operatório do paciente por meio de exame físico e hematológico a cada 30 dias, no entanto não ouve presença de complicações tardias como estenose uretral, nem presença de alterações significativas nos exames no período realizado.

\section{Discussão}

A parafimose traumática é uma afecção comumente diagnosticada em cães adultos (MacPhail, 2014), corroborando com os achados do atual relato. Nos casos em que a parafimose não obtém bons resultados com o tratamento clínico, e casos em que o pênis apresenta comprometimento tecidual, o tratamento de eleição é o cirúrgico (MacPhail, 2014). O paciente em questão apresentava exposição crônica do pênis há 10 dias pós traumatismo. Embora não tenham sido observadas áreas de necrose, foi possível evidenciar um comprometimento tecidual com presença de regiões de fibrose, o que gerou estenose na região de óstio uretral, e como medida terapêutica adotou-se a penectomia.

O diagnóstico de parafimose é baseado principalmente na avaliação clínica do pênis e os exames de imagem e laboratoriais são geralmente inespecíficos. Um uretrograma poderia auxiliar na obtenção de dados para análise do grau de comprometimento da uretra peniana, no entanto não foi possível a realização do exame no paciente (MacPhail, 2014).

De acordo com Burrow et al. (2011), nos casos de parafimose crônica, especialmente nos pacientes com áreas de necrose peniana, as principais técnicas empregadas são amputação do pênis seguida da 
reconstrução prepucial e uretrostomia. Como o paciente em relato apresentava comprometimento no início do óstio uretral, identificado pela incapacidade de realizar a sondagem e a presença de retenção urinária, o tratamento empregado foi a penectomia total. A técnica de uretrostomia escrotal foi realizada conforme recomendado por (Birchard \& Sherding, 2008). A técnica uretrostomia na região do escroto diminui as chances de estenose uretral e hemorragia local, pois a uretra se apresenta mais calibrosa e superficial nessa região, e circundada por um menor volume de tecido cavernoso peniano (MacPhail, 2014).

As principais complicações pós-cirúrgicas são estenose uretral, incontinência urinária e infecção. As infecções do trato urinário ocorrem via migração de bactérias da flora natural do trato urinário para regiões estéreis (MacPhail, 2014). No entanto, para contornar as complicações agudas como a estenose uretral e a incontinência urinaria, foi deixada uma sonda de demora número 10 durante as primeiras 72 horas do pós operatório, como descrito por Campelo Junior et al. (2016), sendo observados bons resultados com a diminuição da incontinência urinária do período pôs cirúrgico e a ausência de estenose uretral (Slatter, 2007).

\section{Conclusão}

Concluiu-se que nos casos de insucesso no tratamento clínico da parafimose, o tratamento cirúrgico se mostra uma opção viável para resolução do problema, dessa forma, no caso em questão, a penectomia com uretrostomia escrotal mostrou-se uma alternativa eficiente como tratamento definitivo para parafimose crônica, proporcionando melhor qualidade de vida ao paciente.

\section{Referências bibliográficas}

Birchard, S. J., \& Sherding, R. G. (2008). Manual Saunders: clínica de pequenos animais. In Ed. Roca (Vol. 3).

Burrow, R. D., Gregory, S. P., Giejda, A. A., \& White, R. N. (2011). Penile amputation and scrotal urethrostomy in 18 dogs. Veterinary Record, 169, 157. https://doi.org/10.1136/vr.100039

Campelo Junior, F. A. C., Macedo, H. J. R., Feitosa, A. S., Alves, A. A., Albuquerque, Á. H., Monteiro, C. L. B., \& Ferraz, R. E. O. (2016). Priapismo em cão tratado com penectomia seguida de uretrostomia: Relato de caso. PUBVET, 11(2), 149-153. https://doi.org/10.22256/pubvet.v11n2.149-153

Gavioli, F. B., Oliveira, R. P., Quadros, A. M., Machado, T. P., Medeiros, B. S., Dalla Palma, M., Linck, C. M., Secchi, P., Cassel, T. G., \& Bisognin, I. (2014). Penectomia com uretrostomia escrotal em cães: relato de quatro casos (2012-2014). Acta Veterinaria Brasilica, 8(2), 86-90.

MacPhail, C. M. (2014). Cirurgia dos sistemas reprodutivo e genital. In T. W. Fossum (Ed.), Cirurgia de pequenos animais. Elsevier.

Nelson, R. W., \& Couto, C. G. (2015). Medicina interna de pequenos animais (Issue 1). Elsevier Editora.

Papazoglou, L. G., \& Kazakos, G. M. (2002). Surgical conditions of the canine penis and prepuce. Compendium, 34(3), 204-218.

Slatter, D. H. (2007). Manual de cirurgia de pequenos animais. Manole.

Volpato, R., Ramos, R. S., Magalhães, L. C. O., Lopes, M. D., \& Souza, D. B. (2010). Afecções do pênis e prepúcio dos cães: revisão de literatura. Veterinária e Zootecnia, 17(3), 312-323.

Recebido: 19 de abril, 2020 .

Aprovado: 20 de junho, 2010.

Disponível online: 28 julho, 2020.

Licenciamento: Este artigo é publicado na modalidade Acesso Aberto sob a licença Creative Commons Atribuição 4.0 (CC-BY 4.0), a qual permite uso irrestrito, distribuição, reprodução em qualquer meio, desde que o autor e a fonte sejam devidamente creditados. 